\title{
SERÁ MESMO QUE O MAGISTÉRIO ATUAL É FORMADO PELA "SELEÇÃO DOS PÉSSIMOS"?
}

\author{
IS IT THAT THE ACTUAL TEACHING IS FORMED BY THE \\ "SELECTION OF THE BAD"?
}

\section{¿SERÁ MISMO QUE EL MAGISTERIO ACTUAL ES FORMADO POR LA "SELECCIÓN DE LOS PÉSIMOS"?}

Marcelo Ricardo Pereira ${ }^{1}$

\section{RESUMO}

As precárias condições da organização e da prática docente de boa parte da Educação Básica do país, o reduzido trabalho coletivo com pares e gestores, as movediças relações com o saber, com o conhecimento e com a formação, bem como os graves problemas de proletarização, de remuneração e de reconhecimento social e de carreira, têm contribuído severamente para produzir certos modos de ser professor que podem condenar o desenvolvimento das novas gerações e todo um projeto de nação. Com os aportes de autores do campo da formação docente e introduzindo elementos do sintoma subjetivo e do método de orientação clínica na escuta de professores, qualificamos nossos argumentos para pôr em questão se realmente selecionamos ou não aqueles que haveriam de ser ajuizados como "péssimos", sem deixar de mostrar o que podemos fazer diante desse indisfarçável fenômeno.

PALAVRAS-CHAVE: Formação docente. Licenciaturas. Orientação clínica. Sintoma subjetivo.

\begin{abstract}
The precarious conditions of the organization and teaching practice of a good part of the Basic Education of the Brazil, the reduced collective work with peers and school principals, the problematic relations with knowledge and with formation, as well as the serious problems of proletarianization, remuneration and social recognition and career recognition, have contributed severely to producing certain ways of being a teacher that may condemn the development of the new generations and a whole project of a nation. With the contributions of authors in the field of teacher training and introducing elements of the subjective symptom and clinical method in teacher listening, we qualify our arguments to question whether or not we actually select those that would be judged as "bad", without fail to show what we can do before this undisguised phenomenon.
\end{abstract}

KEYWORDS: Teacher training. Bachelor's degrees. Clinical method. Subjective symptoms.

\section{RESUMEN}

Las precarias condiciones de la organización y de al práctica docente de buena parte de la Educación Básica de Brasil, el reducido trabajo colectivo con pares y gestores, las movedizas relaciones con el saber, con el conocimiento y con la formación, así como los graves problemas de proletarización, de remuneración y de reconocimiento social y de carrera, han contribuido severamente a producir ciertos modos de ser profesor que pueden condenar el desarrollo de las nuevas generaciones y de todo un proyecto de nación. Con los aportes de autores del campo de la formación docente e introduciendo elementos del síntoma subjetivo y del método de orientación clínica en la escucha de profesores, calificamos nuestros argumentos para poner en cuestión si realmente seleccionamos o no aquellos que han sido juzgados como "pésimos", sin dejar de mostrar lo que podemos hacer ante este innegable fenómeno.

PALABRAS-CLAVE: Formación docente. Profesorado. Orientación clínica. Síntoma subjetivo.

\footnotetext{
${ }^{1}$ Doutor em Educação - Psicologia e Educação - Universidade de São Paulo (USP) - São Paulo, SP - Brasil. Professor Associado de Psicologia, Psicanálise e Educação - Faculdade de Educação, Universidade Federal de Minas Gerais (UFMG) - Belo Horizonte, MG - Brasil. E-mail: marcelorip@hotmail.com
}

Submetido em: 01/10/2017 - Aceito em: 25/07/18

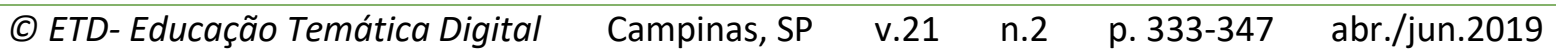




\section{INTRODUÇÃO: DE ONDE PARTIMOS}

As precárias condições da organização e da prática docente de boa parte da Educação Básica do país, o reduzido trabalho coletivo com pares e gestores, as movediças relações com o saber, com o conhecimento e com a formação, bem como os graves problemas de proletarização, de remuneração e de reconhecimento social e de carreira, têm contribuído severamente para produzir certos modos de ser professor que podem condenar - se já não condenam - o desenvolvimento das novas gerações e todo um projeto de nação. Afora algumas poucas iniciativas realmente louváveis, os inúmeros institutos de educação superior do país, os vários estabelecimentos de formação de professores, de cursos de aprimoramento, de especialização e de "reciclagem" - esse termo abominável - podem estar corroborando para o explícito aligeiramento da formação, para uma teorização apartada do real, para uma inflação retórica, ideativa e individualista, como também para uma profissionalização calcada em níveis bastante sofríveis de repertório, curiosidade, criatividade e desejo.

Quadro funesto, é verdade! E será que ele contribui para que o magistério brasileiro reúna hoje aqueles que, porventura, seriam ajuizados como "péssimos", ou seja, aqueles que teriam menos condições profissionais e pessoais de realizá-lo bem?

Para examinar essa questão, recobramos excertos de duas pesquisas que realizamos anteriormente, com o intuito de analisar as causas da perda de autoridade de professores da Educação Básica (PEREIRA; PAULINO; FRANCO, 2011) e o padecimento psíquico de professores de adolescentes (PEREIRA, 2016). Em ambos os trabalhos, anunciamos a presente questãotítulo, mas não a desenvolvemos suficientemente, já que os objetos de estudos de tais pesquisas trilharam outros percursos não menos necessários e que também nos auxiliaram a sedimentar o campo Psicanálise, Educação e Formação de Professores; campo de nosso vívido interesse. Com o presente artigo, pretendemos corrigir essa rota e substanciar melhor essa questão que, a nosso ver, requer adensamento e precisão. Para isso, lançamos mão também dos aportes de autores do campo estrito da formação de professores, visando a qualificar nossos argumentos para pôr em questão se realmente selecionamos ou não aqueles que podem ser considerados como "péssimos" e o que fazer diante desse indisfarçável fenômeno.

\section{QUESTÕES DE MÉTODO}

Para as duas pesquisas em referência (PEREIRA; PAULINO; FRANCO, 2011; PEREIRA, 2016), desenvolvemos uma metodologia que denominamos "pesquisa-intervenção de orientação clínica". Tratou-se de investigações que tinham também o caráter de intervenção, no sentido de levar cada professor a refletir sobre sua prática, a compreender fenômenos, a destravar identificações, a pensar ações e a elaborar-se subjetivamente. Baseando-nos no princípio técnico e seminal da psicanálise, que Sigmund Freud (1914/1980) denominou "recordar, repetir, elaborar", demos à pesquisa um direcionamento clínico sem ser

$\begin{array}{llllll}\text { (C) ETD- Educação Temática Digital } & \text { Campinas, SP } & \text { v.21 } & \text { n.2 } & \text { p.333-347 } & \text { abr./jun.2019 }\end{array}$


propriamente terapêutico, mas, antes, voltado para uma análise estritamente social, reflexiva e elaborativa do real. Seguimos, assim, a tradição do pensamento de vários autores que aplicam a escuta clínica ao campo social, ou seja, intervimos "nos lugares onde os sintomas contemporâneos são recolhidos. Isso não quer dizer que eles sejam entendidos ou tratados, mas sim que deixam traços em alguns lugares" (LAURENT, 2007, p. 177).

Importa salientar que a "pesquisa-intervenção de orientação clínica", ao trabalhar as singularidades discursivas e não tanto as regularidades (PEREIRA, 2016), vai além da "pesquisa-ação" e da "pesquisa participante". Em uma perspectiva diferente daquela dos cientistas sociais, buscamos menos as macrocategorias sociais e mais as formas singulares e microfísicas do ser falante. Com efeito, enquanto sociólogos, historiadores, pedagogos e outros pensadores centram-se na reconstituição e compreensão regular dos acontecimentos e dos discursos, um trabalho de orientação psicanalítica - sem desprezar esse princípio centra-se mais nos modos singulares como um acontecimento é sorrateiramente repetido ao ser narrado, e não apenas recordado ou contado. Somos menos pelos fatos, consciências ou cronologias e mais pela repetição singular que as falas e os silêncios dão a conhecer no que tentam igualmente ocultar. Nesse sentido, dizemos que realizamos pesquisas com sujeitos e não sobre eles.

Assim, não estamos exclusivamente interessados em retratar a realidade vivida pelo professor, como parece fazer a maioria das pesquisas sociais e de humanidades, mas em verificar os efeitos subjetivos de tal realidade em sua própria pessoa, para que ele tenha a chance, talvez, de modificá-la ou modificar-se nela. O que eu fiz com o que fizeram de mim é o princípio sartreano que nos serve como norte, em associação direta à questão freudiana que fundamentou a cura de um de seus analisandos, se não de todos: qual é a sua responsabilidade na desordem da qual você se queixa? Eis a base fundamental na qual se alicerça o elemento clínico de uma pesquisa-intervenção.

Apesar de muito empregada na psicologia social e de não ser um modelo investigativo exclusivo da psicanálise, a pesquisa-intervenção tem, nesse último campo de saber, uma sustentação bastante fértil. Justamente por sua longa tradição clínica na escuta das formas de subjetivação ao fazer falar aquele que sofre, a psicanálise vem somar-se a esse tipo de pesquisa, propondo que se investigue algo e, ao mesmo tempo, se libere a palavra, fazendoa circular em francos espaços de fala (MANNONI, 1973). Busca-se, com isso, "levar o sujeito a produzir o que não se espera: uma novidade, um novo significante, uma fala plena. Algo que o surpreenda e que o subjetive" (PEREIRA, 2016, p. 74). 
É fundamental que o leitor entenda que a clínica não se reduz às práticas de consultórios de médicos, psicólogos e psicanalistas, devendo ser tomada como uma "atitude" ou uma "conduta" que permite pôr em marcha um sujeito em constante reflexão, para que ele tenha a chance de fazer sua subjetividade realizar-se. A clínica será esse lugar privilegiado de acontecimento do sujeito, de fazê-lo vir à superfície e inscrever-se como efeito de uma atitude. Nesse sentido, concordamos com André Green (2004, p. 11) quando ele escreve que "existe em psicanálise não somente uma teoria da clínica, mas um pensamento clínico, isto é, um modo original e específico de racionalidade extraído da experiência prática".

Mireille Cifali (2001) é precisa quando recupera a proposição de Jacques Ardoino para dizer que é clínico aquilo que deseja apreender o sujeito através de um sistema de relações cujo prático se reconheça efetivamente envolvido com a transformação daquele que sofre. Na realidade, buscamos recortar o caráter repetitivo daquilo que não anda bem no sujeito, que doravante denominaremos "sintoma", intervindo pontualmente, com a finalidade de ajudar esse sujeito a fazê-lo vacilar. Fazer o sintoma vacilar é auxiliar cada um a formalizá-lo, a demover-se de tal formalização e a destravar identificações para alcançar algum modo de elaboração subjetiva.

Para isso, na pesquisa sobre a autoridade docente, conhecemos fragmentos da experiência profissional, da vida biográfica e, porventura, do sintoma de 46 professores dos ensinos público e privado e de mais de 50 do ensino público na pesquisa sobre padecimento psíquico. Lançamos mão de diversas fontes documentais para entender fenômenos e escolher amostragens de instituições e de docentes. Empregamos também o contato direto a partir da ferramenta "bola de neve" (DEWES, 2009), por meio da qual alguns sujeitos sabem reconhecer e indicar outros porque, em parte, conhecem atitudes ou comportamentos comuns que os tornam próximos. Nos ambientes institucionais, solicitamos respostas escritas para duas questões de partida ou criamos "espaços de fala" (BESSET; COUTINHO; COHEN, 2008, p. 92), em encontros grupais (em quantidade de 1 a 5) de até 10 sujeitos. Procedemos, também, a "observação de singularidades" (PEREIRA, 2016; BARROS; LEHFELD, 1986), voltada mais às situações contingentes e microfísicas da prática de alguns professores. Dos 46 da primeira pesquisa e dos mais de 50 da segunda, escolhemos, respectivamente, 24 e 15 para realizarmos as "entrevistas de orientação clínica" (PEREIRA; PAULINO; FRANCO, 2011; PEREIRA, 2016), que são entrevistas de profundidade, não dirigidas, com caráter de formalização do sintoma para fins de intervenção. Também fizemos uso do "diário de bordo" (BARROS; LEHFELD, 1986) e do "diário clínico" (FERENCZI, 1932/1993) para o registro tanto de informações, experiências e impressões do material coletado, numa atitude de refletir sobre a prática, quanto da pessoalidade dos próprios pesquisadores, numa atitude de refletirem-se na prática. 


\section{A "SELEÇÃO DOS PÉSSIMOS”}

A discutível sentença não pouco dramática de Lauro de Oliveira Lima (1995, p. 39) - “o magistério é formado pela seleção dos péssimos" - guarda alguma razão prática que nos leva a admitir que convém examiná-la antes de, irrefletidamente, rechaçá-la.

Para o autor, os piores alunos tendem a se tornar professores e, como tal, são transformados em "robôs" que repetem e seguem instruções determinadas pelo "monstrengo burocrático" que os domestica definitivamente. Os professores, geralmente, se põem a serviço dos valores socioculturais mais "retrógrados" e seus esquemas de trabalho invertem seus valores morais e desfazem seu compromisso com uma prática educativa humanizadora. Não é incomum professores mentirem sobre o real conhecimento que transmitem ou se iludirem dizendo para si mesmos que fazem o melhor que podem. Em sua atividade profissional, o docente repete o modelo arcaico de verbalização, apesar de sua evidente ineficácia histórica. As escolas não são locais de atividades motora, verbal e intelectual, mas pequenos e sufocantes auditórios compartimentalizados, onde "oradores fanhosos" recitam, aos brados, textos decorados. Enquanto recitam, plateias cativas de alunos apáticos enervam-se, aguardando o sinal de término da aula que suspende a "verborragia magisterial". Lima (1995) acha impressionante a alegria com que os alunos recebem tal sinal, não se surpreendendo com o fato de o atual professorado ser desautorizado e não merecedor do respeito sociocultural da comunidade, refletidos no desprestígio que determina o valor de sua remuneração.

Para além da estigmatização de apenas um dos atores do fenômeno - o professor -, o quadro se complica quando observamos um fragmento da história recente da profissão. Com a democratização do ensino ao longo do século $X X$, presenciamos o crescimento do número de estabelecimentos escolares, o que resultou, paulatinamente, na multiplicação do número de professores - agora, profissionais - para atender essa demanda aumentada. O ideal republicano de o estado levar a escolarização às massas foi uma conquista inexorável, mas também resultou em problemas substanciais, entre eles, a pouca ascensão salarial e o desprestígio social aos quais os "novos" professores foram sujeitados ao longo desse período. Outro problema foi o quanto esses "novos" deixaram de ser quase que exclusivamente os fidalgos - os filhos de algo ou os filhos de famílias nobres - e passaram a proceder de ordens socialmente menos legitimadas. A classe trabalhadora começou a produzir docentes: hoje, eles descendem, em sua maioria, de pequenos comerciantes, de operários industriais, de ambulantes, de pais com pouca instrução, entre tantos que compõem as massas. Ora, uma vez oriundos das esferas mais pobres da população, esses "novos" docentes receberam e recebem atenção minuciosa dos agentes formadores e institutos de educação superior, que inculcam certa mentalidade da profissão que faz com que pobres governem pobres. Em regra, o professor brasileiro não escapará aos desígnios do estado de governar as massas, de educálas em seu nome, mesmo que não seja claro o projeto de nação para o qual isso deva ser feito

$\begin{array}{llllll}\text { (c) ETD-Educação Temática Digital } & \text { Campinas, SP } & \text { v.21 } & \text { n.2 } & \text { p.333-347 } & \text { abr./jun.2019 }\end{array}$


- projeto que, aliás, desde as capitanias, não demonstra ir além de políticas espúrias, enriquecimentos exclusivos, concentração de bens, patrimonialismos escravistas. Não surpreende, então, os visíveis problemas de proletarização e de reconhecimentos social, laboral e financeiro pelos quais passa hoje um professor ordinário da Educação Básica.

Sendo o professor, majoritariamente, originário das classes populares, não é incomum ele ter sido criado nesse meio e, à custa de esforço ou acaso, ter obtido, à contramão da vida, vitória em sua trajetória escolar. Poucos entre seus colegas de infância puderam contar com o mesmo destino. Mas, uma vez estando no curso de formação docente, ele logo conhecerá o peso institucional para fazê-lo demover-se dos vícios de sua origem. O aspirante a "novo" professor, para licenciar-se como docente, será submetido aos modos mais sutis ou aos mais explícitos de vigilância moral e intelectual das agências formadoras. Dia após dia, Ihe será inculcada a ideia de exercer seu ofício de maneira imaculada e fascinante, se tornando um exemplo a seguir. Bem ou mal, isso comporá a pastoral pedagógica na qual ele deverá submergir. Porém, uma vez formado, o mais comum é que venha a ministrar aulas em escolas também de classes populares, quando não o faz em alguma escola de sua comunidade de origem. Encontrar-se-á, pois, entre iguais; e certo atavismo sempre haverá de lhe sobressaltar. Logo verá que já conhece os meninos e as meninas do lugar onde vive, seus futuros alunos; conhece também suas famílias, o que fazem, por onde andam, os delitos, os desvios, os comportamentos, os hábitos. Da mesma forma, as famílias da comunidade, os alunos, os moradores o conhecem; sabem igualmente de seus hábitos, desvios e intimidades. Como revela um professor que se encontrava em um bar perto de sua casa e também de sua escola quando um grupo de alunos de uma de suas turmas passa em zombaria, dizendo: "aí, profe, bebendo, hein?"

Ora, como manter entre seus iguais certa ascendência baseada num padrão de conduta moral imaculada? Como manter uma diferença exemplar num ambiente que preserva pouco sua intimidade? O professor, em nossos tempos, deve fazer valer o apagamento da diferença social e cultural e, ao mesmo tempo, a restauração de seu valor moral imaculado, fascinante que a pastoral e a maquinaria pedagógicas tratam de lhe inculcar.

A pedagogia é, via de regra, a ciência de base moral e racionalista que está no centro desse impasse. Seus profissionais parecem pouco entender que ela é, como diz Maurice Tardif (2005, p.127), "uma tecnologia constantemente transformada pelo trabalhador", que nunca possui indicações muito claras e precisas sobre os propósitos e objetivos do ensino. Porém, seja por meio de seus dogmas e saberes sobre o ato de ensinar, seja por meio de sua própria proposta de formação, o licenciando espera resolver com as disciplinas pedagógicas os dilemas cotidianos de sua prática, as incertezas, as descontinuidades, as subversões. Falta-Ihe admitir que, muitas vezes, agirá sem saber ao certo se os resultados de seu trabalho serão atingidos. Tais resultados estarão continuamente imbricados num conflito de interpretações

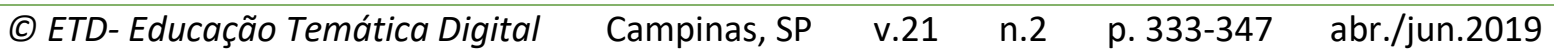


que revela um número incoerente de expectativas sociais sobre o seu trabalho e/ou sobre o trabalho da escola.

Não é de se estranhar que vários alunos menos brilhantes, ou seja, que atravessaram sua escolarização com sérios problemas pedagógicos e de aprendizagem, tendam a buscar cursos de licenciatura com menos exigências para o ingresso no ensino superior. O próprio Sistema de Seleção Unificada (Sisu) - fomentado por governos ditos populares (e ainda mantido pelos governos subsequentes) -, que vem tentando dar acesso mais democrático às universidades públicas brasileiras, pode ter colaborado para candidatos menos identificados com a profissão docente ingressarem em cursos de formação de professores. Isso pelo simples e desastroso fato de ser essa a única chance de acesso desses candidatos ao ensino público superior de qualidade; ensino historicamente seletivo e excludente.

Daí, sem muitas opções, eles têm a chance de se formarem e de se tornarem professores. A exceção fica por conta daqueles muitos que evadem ou daqueles poucos que vão se identificar realmente com a profissão e realizá-la com desejo. Vários licenciandos não atuarão como professores e se manterão em ofícios medianos, às vezes burocráticos, boa parte da vida. Outros, sem esconder seus desentusiasmos, exercerão a profissão de professor normopaticamente, sem muita implicação nem desgaste, reduzindo e nivelando a complexidade da profissão a um ofício repetitivo e ordinário. Outros, ainda, a exercerão como complemento de renda, como "um bico", ao qual dedicarão poucas horas por semana, sem necessariamente se implicarem com alguma transformação da própria profissão. Outros, entre tantos, a realizarão de maneira por vezes implicada, mas sem estrutura pessoal ou profissional suficiente que Ihes possibilite efetivá-la sem, de fato, adoecer ou apresentar algum modo de "sofrimento no trabalho" (LEGUIL, 2012). Enfim, o que se especula aqui é o quanto muitos tendem a não esconder a infelicidade em realmente atuar como professores. Talvez esse fato contribua para que eles realizem o ofício sem muito desejo, repertório, curiosidade e criatividade - requisitos básicos para a profissão -, tornando-se mais susceptíveis à repetição e à adesão às regras burocráticas que largamente os domesticam.

Em geral, professores nessas condições tendem a ser mais conservadores, mais conformistas, menos ousados e, muitas vezes, posicionam-se politicamente de modo reacionário. A melhor didática é, pois, aquela que Ihes permite sobreviver a cada dia letivo, mesmo que para isso tenham que repetir a todo o momento que fazem o melhor que podem. Um professor nessas condições pode até realizar - e realiza - muitos cursos de formação continuada, mas, na verdade, ele estuda muito pouco (tem tempo restrito para isso), não se desafia a ampliar seu repertório e padece de não ter suficiente base familiar, social e escolar que the permita fazê-lo. Submete-se, sem muito esforço, a um verdadeiro ritual de desqualificação, sem condições nem incentivo para se aperfeiçoar, tampouco para evitar cumprir conteúdos extensos e pouco adequados à carga horária; conteúdos muitas vezes divorciados das necessidades sociais dos alunos. Seus esquemas de trabalho, na realidade,

$\begin{array}{llllll}\text { (C) ETD-Educação Temática Digital Campinas, SP } & \text { v.21 } & \text { n.2 } & \text { p. 333-347 } & \text { abr./jun.2019 }\end{array}$


colaboram para inverter sua coragem moral e desfazem o fluxo de poderem agir em conformidade com o seu desejo.

“Não pode ser coincidência, não - revela uma professora de adolescentes de escola pública em sua entrevista de orientação clínica -, toda pessoa mal-humorada, estranha, esquisita vem parar na escola [...]. Será que junta muita gente estranha na escola ou as pessoas vão ficando desse jeito nela?". Como essa professora, podemos recolocar a questão e, ao mesmo tempo, interrogar a premissa discutível de Lauro Lima: Será que junta muita gente péssima na escola ou as pessoas vão ficando péssimas ao se formarem e estarem nela?

\section{QUE PROFESSORES NOSSO ENSINO SUPERIOR PRODUZ?}

Estudos recentes nos ajudam a responder a questão. Primeiramente, os "números". De acordo com Bernardete Gatti e Elba Barreto (2009), ${ }^{2}$ dois terços de nossos licenciandos são mulheres, sendo quase $40 \%$ deles provenientes de famílias com renda de até 3 salários mínimos (chegando a $90 \%$ se o corte for de até 10 salários). Um em cada 10 é oriundo de lares de pais analfabetos e outros 6 de cada 10, de pais cuja escolaridade se limitou ao ensino fundamental. Dois terços dos licenciandos cursaram integralmente o Ensino Médio em escolas públicas (esse índice chega a $83 \%$ se considerarmos também aqueles que mesclam escolas públicas e privadas). A média de pontos no Enem (Exame Nacional do Ensino Médio) de 2008 para tais alunos foi 37,27 (em 100), com médias inferiores a essa em anos precedentes, o que mostra que "a escolaridade realizada em escolas públicas evidencia grandes carências nos domínios de conhecimentos básicos. É com esse cabedal que a maioria dos licenciandos adentra nos cursos de formação de professores" (GATTI, 2010, p. 1365).

Durante tais cursos, é curioso perceber que quase $70 \%$ dos materiais de estudo se reduzem a apostilas, resumos e fotocópias de trechos de livros. Menos de $2 \%$ desses materiais são compostos por artigos em periódicos especializados. Se examinarmos as avaliações, $90 \%$ delas são circunscritas às provas escritas e aos trabalhos de grupo, sendo importante notar a diferença de seu emprego no curso de Pedagogia e nas demais licenciaturas. Enquanto no primeiro prevalecem os trabalhos de grupo (50\% contra $37 \%$ de provas), nas outras licenciaturas há uma inversão ( $60 \%$ de provas contra $29 \%$ de trabalhos de grupo). Deve-se ressaltar que, no caso da Pedagogia, uma razoável parcela dos alunos pode passar sem ter uma experiência sequer de avaliação individual no decorrer do curso. Ainda assim, nota-se o baixo índice de conclusão em ambas as formações (24\%), ou seja, mais de dois terços dos alunos matriculados em cursos de Licenciatura não se formam professores.

\footnotetext{
${ }^{2}$ A pesquisa, realizada para a UNESCO, analisou os seguintes cursos de formação de professores: Biologia, Física, Geografia, História, Letras, Matemática, Química e Pedagogia; com base no Enade (Exame Nacional de Cursos) de 2005, abrangendo mais de 137 mil sujeitos. É a pesquisa quantitativa mais abrangente feita para tal fim desde a redemocratização do país, após a década de 1980.
}

$\begin{array}{llllll}\text { (C) ETD- Educação Temática Digital Campinas, SP } & \text { v.21 } & \text { n.2 } & \text { p. 333-347 } & \text { abr./jun.2019 }\end{array}$ 
Porém, isso não impediu que, entre 2001 e 2006, a oferta de tais cursos praticamente dobrasse na Pedagogia e tivesse um aumento de $50 \%$ nas demais licenciaturas. Foi o período em que eles mais cresceram. A voracidade do mercado pedagógico não inibiu esse incremento, ainda que o número de matriculados e o de concluintes dos cursos tenha diminuído. Esse fato denota as facilidades encontradas pelas instituições de formação de professores para ampliar ofertas de cursos de estruturas mais baratas, mesmo a despeito do aparente desinteresse do público alvo e dos esforços inócuos de se tentar reverter o desprestígio histórico da profissão. Mais de $60 \%$ desses cursos estão nas universidades, sobretudo em instituições privadas. Eis outro aspecto que convém considerar.

Segundo Júlio Emílio Diniz-Pereira (2015), entre 1995 e 2007, o número de instituições privadas de Ensino Superior aumentou quase $200 \%$ contra $19 \%$ de instituições públicas. Entre as dez maiores em número de matriculados, apenas três são do setor público, resultando na multiplicação do que o autor vai chamar "universidades-empresas". São instituições "consideradas de massa e têm como principais características a cobrança de mensalidades mais baixas e um número muito grande de alunos" (DINIZ-PEREIRA, 2015, p. 275). Predominam nelas estudantes que são trabalhadores jovens, de classes populares, moradores de centros urbanos e que estudam à noite. Em cidades pequenas e médias, onde há ausência de instituições públicas de Ensino Superior, tendem a prevalecer as faculdades isoladas e, de maneira alastrada, a EaD (Educação a Distancia). De acordo com as fontes do autor, entre 2002 e 2007, a EaD obteve um crescimento impressionante de mais de 800\%. "A iniciativa privada tendo explorado todos os caminhos da educação presencial (cursos de fácil oferta bacharelados, licenciaturas e tecnológicos) e experimentado os limites da demanda, bateu às portas do MEC solicitando credenciamento para atuar com a EaD" (GIOLO, citado por DINIZPEREIRA, op.cit., 276).

O fato é que, conforme o Inep (Instituto Nacional de Estudos e Pesquisas Educacionais Anísio Teixeira), em 2011, 26\% dos cursos de graduação do país foram de Licenciatura presencial e a distancia, abocanhados majoritariamente por instituições privadas. Desse $26 \%$, $43 \%$ das matrículas foram realizadas na modalidade a distancia, tornando-se, com efeito, a maior proporção entre os cursos de graduação no geral. Em outras palavras: uma expressiva parcela de nossos atuais professores da Educação Básica foi formada sem nunca ter pisado fisicamente o solo de uma universidade ou instituição superior, exceto em momentos de eventos ou de obrigatoriedades administrativas.

Ao que parece, repisamos o barro. Há muitas décadas discutimos os mesmos problemas, o mesmo desprestígio docente, a mesma condição desfavorável de sua prática, o mesmo aligeiramento de sua formação... Autores como Gatti (2010), André (2010), Santos (2015) e Diniz-Pereira (2015; 2016) não escondem o que deve ser feito para reverter essa situação crônica de incitação dos "péssimos". Preconizam a necessidade de uma ampla e verdadeira revolução nas estruturas institucionais formativas e nos currículos, que interrogue,

$\begin{array}{llllll}\text { (C) ETD-Educação Temática Digital Campinas, SP } & \text { v.21 } & \text { n.2 } & \text { p. 333-347 } & \text { abr./jun.2019 }\end{array}$


inclusive, sua forte tradição disciplinar. Tal revolução abarca desde uma melhor estruturação do Ensino Médio até a regulação de ofertas indiscriminadas de licenciaturas por parte de instituições do setor privado; isso sem contar as necessárias regulações referentes a cursos a distancia, noturnos, de curta duração, aos identificados mais com o bacharelado do que com docência, bem como à formação apostilada e apartada da realidade cotidiana.

\section{A urgência em qualificar um grande número de educadores para uma população escolar crescente sem o correspondente investimento financeiro por parte do governo leva à repetição de erros cometidos em um passado próximo e, consequentemente, corre-se o risco de reviver cenários de improvisação, aligeiramento e desregulamentação na formação de professores para o país (DINIZ- PEREIRA, 2016, p. 157).}

Mas se esses números problemáticos e as sólidas análises de sociólogos, historiadores, pedagogos etc. são tão atordoantes, por que mantemos a realidade que os produz? Por que não a convulsionamos ou não a transformamos? Por que muitos daqueles que participam dessa estrutura - os professores, inclusive - não demonstram musculatura suficiente para revolucioná-la? O que, afinal, nos faz tão aderidos a essa situação?

Há que se considerar que do outro lado da mesma moeda estão os "sujeitos"! Talvez haja algo que diga respeito a esses sujeitos que, como tais, são produzidos e também produzem o quadro que tristemente se apresenta. Não obstante, nas pesquisas-intervenções de orientação clínica citadas inicialmente (PEREIRA; PAULINO; FRANCO, 2011; PEREIRA, 2016), examinamos os efeitos de tal quadro na própria pessoalidade do professor. Elas revelam o quanto, na singularidade subjetiva, alguns professores produzem, em si mesmos, formas de sintoma decorrentes desse quadro. Tais formas, de acordo com nossos estudos, derivam respectivamente dos efeitos de se desautorizarem na função ou de psiquicamente se padecerem ao não conseguirem levá-la a cabo.

Então, se, de um lado, temos os números, do outro, temos os sujeitos e seus "sintomas". E falamos aqui do sintoma psíquico, ou seja, de um fenômeno subjetivo que revela como cada um de nós se apresenta no real. Aliás, habituamo-nos a sempre nos autonomear por meio de nossos sintomas, o que nos condena a uma inércia substancial e contumaz. Diz-se "eu sou deprimido", "eu sou nervoso", "eu sou ansioso", "eu sou alcoólatra", "eu sou pilha fraca"... do mesmo modo que se diz "eu sou fulano de tal". O sintoma psíquico batiza o sujeito e pode fixá-lo a uma condição mórbida de difícil destrave. Na verdade, enquanto o sintoma médico ou biológico é o sinal de uma anormalidade orgânica que deve ser tratada, o sintoma psíquico, além de ser um sinal de que algo não anda bem, estrutura o sujeito e lhe permite alguma forma de satisfação substituta, que faz com que o sujeito se fixe nele sem vacilar. Por exemplo: a depressão pode ser um sinal para um sujeito que se deprecia fortemente e se maltrata por se julgar incapaz de atender as demandas do outro que lhe exige reação, se demitindo subjetivamente; mas, ao mesmo tempo, pode ser aquilo que lhe garante alguma satisfação mórbida por manter atônito esse mesmo outro que, com sua presença incondicional, Ihe recobre de atenção e cuidados. Em outras palavras,

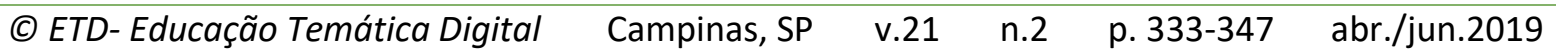


[...] ambivalente, o sintoma psíquico é desfuncionamento e laço; é problema e solução. Ele é um problema, pois incapacita o sujeito a aproveitar a sua vida; mas é também solução porque é a resposta a essa incapacidade, garantindo ao sujeito uma forma específica e substancializada de satisfação no sofrimento (PEREIRA, 2016, p. 81).

O sujeito, por assim dizer, goza com o seu sintoma! E é isso que autoriza Freud a concluir que "o tipo de satisfação que o sintoma consegue, tem em si aspectos estranhos ao próprio sintoma, [ou seja] uma satisfação como sofrimento" (FREUD, 1916-17/1980, p. 427). Portanto, o sintoma psíquico, para o autor, produziria o que ele mesmo denominou "ganho proveniente da doença" (p. 446), um ganho secundário.

E por que introduzimos essa noção de sintoma subjetivo para problematizar os números dos estudos das ciências humanas e sociais? Porque vários professores produzidos pelo Ensino Superior do país não apenas sofrem os efeitos de uma condição e formação docentes desfavoráveis, mas também, como mostram nossas pesquisas de base psicanalítica, tendem a produzir formas substitutas de satisfação com tal sofrimento, fixando-se nelas.

O que queremos dizer é que os sujeitos que compõem o nosso magistério da Educação Básica, formado majoritariamente por mulheres, provenientes das classes populares, com baixos escores no Enem, licenciados sobremaneira em escolas privadas ou em EaD de ensino noturno, com sérios problemas pedagógicos e desidentificados com a profissão, podem produzir formas de sintoma que mais os fixam nessa condição do que os destravam. Mantêmse, assim, sem muitas estratégias de ação para modificar o real ou se modificar nele. $O$ que vimos em nossas fontes foi uma proliferação de queixas, absenteísmos, laudos médicos, afastamentos de trabalho, perícias e pedidos de desvio de função e de saída da sala de aula, frutos contumazes da miséria psíquica pela qual passa cotidianamente não a maioria, mas um número razoável de docentes.

Nossos estudos de orientação clínica mostraram - com base em escritos, espaços de fala, observações de singularidades e entrevistas clínicas - que, apesar de a maior parte conseguir driblar minimamente sua condição docente desfavorável, alguns professores, uma vez impotentes, não criam senão o pior para si mesmos, isto é, modos bastante específicos de sintoma para seu mal-estar laboral. Analisamos vários desses modos: disposições depressivas e melancólicas (os mais comuns), angústias difusas, fenômenos de ansiedade e pânico, desordens da oralidade e da adicção (a exemplo da bulimia, da compulsão alimentar, do alcoolismo) e outros de menor incidência.

Demonstramos empiricamente os possíveis "ganhos provenientes da doença", ou seja, o refugio no sintoma que professores com os quais estivemos empreendem para que sua impotência, sua inabilidade e suas fraquezas conceituais, sociais e políticas, advindas também das condições em que se formaram, sejam narcisicamente disfarçadas ou maquiadas. Entre os desautorizados e os padecidos psiquicamente, muitos demonstram, no que narram sobre suas vidas e práticas, camuflar suas incongruências profissionais e pessoais, bem como seus sofríveis índices de repertório, curiosidade, criatividade e desejo pelo que fazem. Daí, cada um

$\begin{array}{llllll}\text { (C) ETD- Educação Temática Digital } & \text { Campinas, SP } & \text { v.21 } & \text { n.2 } & \text { p.333-347 } & \text { abr./jun.2019 }\end{array}$


a seu modo, antes que suas faltas sejam externadas, alveja o mundo ao redor, atribuindo com alguma razão - às condições de trabalho, à desestruturação da escola e aos confrontos e desinteresses do alunado os motivos do próprio fracasso e da sua demissão subjetiva. Ele parece pouco subjetivar os saberes e os elementos da formação que lhe permitiriam atuar melhor no real. Forma sem se formar: isso o faz ser malsucedido em suas reações, com quase nenhuma condição de elaborar-se ou modificar-se a partir de sua profissionalização.

E o pior: cedido de seu desejo e sem repertório suficiente nem ilusões, ele pouco acredita no aluno, isto é, pouco acredita que pode governá-lo para poder transformá-lo em nome do estado ou de quem quer que seja, num evidente sinal de desistência e desilusão. Logo, percebemos naquele que se diz desautorizado, desrespeitado, desmoralizado ou padecido psiquicamente uma espécie de recuo do desejo e uma clara posição subjetiva de inibir-se antes de se colocar à prova, de refluir-se antes que o avaliem como "péssimo", de cair antes da queda. Arriscaríamos a dizer, com Freud (1893/1980, p. 170), que a "covardia moral" não lhe permite aproveitar sua profissão nem tampouco aproveitar a vida e realizarse. Prefere se evadir e se mimetizar num rosário de reclamações e lamúrias do que interrogar qual é a sua responsabilidade na desordem da qual ele mesmo se queixa.

Por sua vez, no geral, a escola não o ajuda a reverter isso, pois, bem ou mal, ela mais o protege do que o convoca a destravar seus sintomas e a elaborar-se. Na realidade, ela tende a reunir maternalmente no seu interior muitos queixosos ou os que se demitem subjetivamente, sem exigir-lhes maiores implicações ou alterações dessa posição demissionária e lamurienta. Seguindo os desígnios da "maternagem pedagógica" (PEREIRA, 2008 , p. 169), que tende a maternizar sujeitos e procedimentos escolares a ponto de proteger a todos, desconfiamos que muitas escolas da Educação Básica, sobretudo as públicas, podem estar recobrindo as fragilidades de seus membros, exigindo-lhes mais burocracias do que atitudes. Eles parecem reclamar da instituição escolar como se reclama de uma mãe que falha em atender suas constantes demandas orais por alimentação. Desse modo, passamos a admitir que certas escolas tornaram-se um lócus significativo da coalizão dos frágeis ou dos "péssimos", como nomeia Lauro Lima. Mas não dos péssimos em sua origem - afinal, são vitoriosos por terem vencido tantas adversidades para chegarem ao magistério - e sim dos "péssimos" produzidos por essas mesmas escolas e por todo um modelo de vigilância moral e intelectual advindo das instituições formadoras, que atendem a exigência da pastoral pedagógica de querer todos imaculados. Portanto, não selecionamos os péssimos, como denuncia Lauro Lima; nós os produzimos! 


\section{CONCLUSÃO: NO AVESSO DA PRODUÇÃO DOS PÉSSIMOS}

Se for assim, julgamos ser fundamental que formadores, gestores pedagógicos e sistemas educativos em geral entendam que dificilmente conseguiremos avançar sem que algo específico da prática do professor seja recolocado no epicentro do debate. Repensar suas condições de trabalho, sua remuneração, suas relações com o saber e com a formação são essenciais, mas, sobremaneira, precisamos auxiliar o professor a recuperar sua coragem moral para atuar em situações de incerteza e descontinuidades sem se evadir. Também devemos ajudá-lo a dar respostas mais ou menos rápidas mediante tais situações, a lidar com a apatia do alunado sem se tornar igualmente apático e a entender as formas de "ganho proveniente da doença" que, às vezes, suas escolhas e posições pessoais e profissionais the outorgam sem que tenham todo o juízo sobre isso.

E o que fazer? Sugerimos que, ao lado de uma ampla revolução nas estruturas institucionais formativas, nos currículos e nas políticas de remuneração e de carreira, sejam instituídas nas escolas o que denominamos "micropolítica da fala" (PEREIRA, 2016, p. 173 e segs.). Seria uma micropolítica - em razão de ser circunscrita à singularidade de cada instituição e não a uma política pública global - que levasse em conta também a escuta e a fala daqueles que realizam e se embaraçam cotidianamente com o ato de ensinar. Acreditamos que seja plausível aos formadores e aos gestores de professores que admitem a orientação psicanalítica instituírem "fóruns" ou "espaços de fala" individuais e coletivos nos quais os docentes possam expor livremente seus impasses, experiências e subjetividades; que tenham, com isso, a chance de destravar formas fixas de sintoma e elaborar-se. A fala respeitaria o princípio freudiano da "associação livre", sendo, portanto, não uma fala qualquer, mas uma fala implicada, uma fala que se responsabiliza pelo que se diz, ou seja, uma "fala plena", como conceituou Jacques Lacan (1953/1998)!

Essa "fala plena" alcançaria o estatuto fundante de outra política para o exercício docente, capaz de admitir algo de um laço inédito de ordem clínica. Longe de se assemelhar a uma psicoterapia grupal ou qualquer modalidade stricto sensu da psicologia, propomos uma análise constante da prática profissional na qual o protagonista não seria senão aquele que a realiza cotidianamente: o professor. Seria, assim, uma micropolítica que estimularia gestos que fizessem vacilar o sintoma e propiciassem destraves, dessubstancializações e deslocamentos subjetivos. Da mesma forma que conduzimos nossas pesquisas-intervenções liberando a palavra para que ela pudesse surpreender e produzir efeitos inéditos de elaboração, pensamos ser vital que haja nas escolas um profissional - na pessoa do pedagogo, do coordenador pedagógico ou do formador de professores - que opere inspirado na técnica freudiana "recordar, repetir e elaborar". Para isso, ele deverá ter sido escutado subjetivamente, ter interrogado seus próprios sintomas, consentir com o inconsciente e oferecer-se como suporte transferencial de suposto saber para os que the procurarem. Reforçamos a premissa de que aqueles que acompanham os profissionais do campo da educação devem, necessariamente, dispor-se a escutar e a acolher os sintomas que surgem

$\begin{array}{llllll}\text { (C) ETD- Educação Temática Digital } & \text { Campinas, SP } & \text { v.21 } & \text { n.2 } & \text { p. 333-347 } & \text { abr./jun.2019 }\end{array}$


no interior desse campo. Esse profissional não é menos do que aquele que promova uma escuta apurada e, igualmente, faça intervenções mínimas - nunca longas -, sempre um pouco atrás e sem moralismos, de modo a fazer a palavra circular em francos "espaços de fala". Lembremos que a clínica trabalha com a palavra, mas essa palavra é, sobretudo, a do sujeito, e não de quem o dirige. Eis o coração do método psicanalítico que requeremos aqui para o campo da Psicanálise e Educação, sem, é claro, reduzi-lo a alguma forma de terapêutica.

Sabemos que muitos outros campos das chamadas Ciências da Educação, cada um a seu modo, contribuíram e contribuem para o avanço das práticas profissionais de professores nesse vasto território de domínio pedagógico. Mas queremos crer que o cabedal teóricometodológico aqui anunciado tenha demonstrado as possíveis contribuições da Psicanálise e Educação para a formação e prática de professores: uma maneira genuína, própria desse campo, que tão-somente ele haveria de instituí-la como tal.

\section{REFERÊNCIAS}

ANDRÉ, Marli. Formação de professores: a constituição de um campo de estudos. Educação, v.33, n.3, p. 174-181, 2010.

BRASIL. Instituto Nacional de Estudos e Pesquisas Educacionais (INEP). Censo da Educação Superior: 2011 - resumo técnico. Brasília: MEC/INEP, 2013.

BARROS, Adil; LEHFELD, Neide. Fundamentos de metodologia. São Paulo: McGraw-Hill, 1986.

BESSET, Vera; COUTINHO, Luciana; COHEN, Ruth. Pesquisa-intervenção com adolescentes: contribuições da psicanálise. In: CASTRO, Lúcia; BESSET, Vera (Orgs.). Pesquisa-intervenção na infância e juventude. Rio de Janeiro: Trarepa/FAPERJ, 2008.

CIFALI, Mireille. Conduta clínica, formação e escrita: In: PERRENOUD, Philippe (Org.). Formando professores profissionais: quais estratégias? Quais competências? 2. ed. Porto Alegre: Artmed, 2001.

DEWES, João Osvaldo. Amostragem em bola de neve e respondent-driven Sampling [monografia]. UFRGS: Porto Alegre, 2009.

DINIZ-PEREIRA, Júlio Emílio. Formação de professores da Educação Básica no Brasil no limiar dos 20 anos da LDBEN. Notandum, v.42, p. 139-160, 2016.

DINIZ-PEREIRA, Júlio Emílio. A situação atual dos cursos de licenciaturas no Brasil frente à hegemonia da educação mercantil e empresarial. Revista Eletrônica de Educação, v.9, n.3, p. 273-280, 2016.

FERENCZI, Sándor [1932]. Diário clínico. Rio de Janeiro: Imago, 1993.

FREUD, Sigmund [1893]. Casos clínicos: miss Lucy R. Edição Brasileira das Obras Completas. Rio de Janeiro: Imago, 1980, v. 2.

$\begin{array}{llllll}\text { (C) ETD- Educação Temática Digital } & \text { Campinas, SP } & \text { v.21 } & \text { n.2 } & \text { p. 333-347 } & \text { abr./jun.2019 }\end{array}$


FREUD, Sigmund [1914]. Recordar, repetir, elaborar. Edição Brasileira das Obras Completas. Rio de Janeiro: Imago, 1980, v. 12.

FREUD, Sigmund [1916-17]. Conferências introdutórias sobre psicanálise. Edição Brasileira das Obras Completas. Rio de Janeiro: Imago, 1980, v. 16.

GATTI, Bernardete. Formação de professores no Brasil: características e problemas.

Educação e Sociedade, v.31, n.113, p. 1355-1379, 2010.

GATTI, Bernardete; BARRETO, Elba. Professores do Brasil: impasses e desafios. Brasília: UNESCO, 2009.

GREEN, André. La pensée clinique. Paris: Odile Jacob, 2004.

LACAN, Jacques [1953]. Função e campo da fala e da linguagem em psicanálise. In: Escritos. Rio de Janeiro: Zahar, 1998.

LAURENT, Éric. A sociedade do sintoma. Rio de Janeiro: Contra Capa, 2007.

LEGUIL, François. Souffrances au travail. Paris: AST, 2012.

LIMA, Lauro de Oliveira. Para que servem as escolas? Petrópolis: Vozes, 1995.

MANNONI, Maud. Éducation impossible. Paris: Seuil, 1973.

PEREIRA, Marcelo Ricardo. A impostura do mestre. Belo Horizonte: Fino Traço/Argvmentvm, 2008.

PEREIRA, Marcelo Ricardo. O nome atual do mal-estar docente. Belo Horizonte: Fino Traço/Fapemig, 2016.

PEREIRA, Marcelo Ricardo; PAULINO, Bárbara; FRANCO, Raquel. Acabou a autoridade? Professor, subjetividade e sintoma. Belo Horizonte: Fino Traço/Fapemig, 2011.

SANTOS, Lucíola Licínio. A pesquisa nos campos do currículo e da formação de professores. Revista Brasileira de Pesquisa sobre Formação Docente, v.7, n.12, p. 11-22, 2015.

TARDIF, Maurice. Saberes docentes \& formação profissional. Petrópolis: Vozes, 2005.

\section{AGRADECIMENTOS:}

CNPQ E FAPEMIG.

\section{Revisão gramatical realizada por:}

Darci Motta

E-mail: .darcimotta@hotmail.com

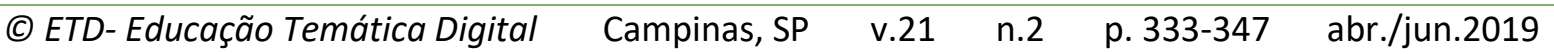

